\title{
Orbitofacial mucormycosis with unusual pathological features
}

\author{
DANIEL M. ALBERT, ${ }^{2}$ ROBERT L. LESSER, ${ }^{2}$ ROBERT C. CYKIERT, ${ }^{2}$ AND \\ Z. NICHOLAS ZAKOV
}

From the ${ }^{1}$ Howe Laboratory of Ophthalmology, Massachusetts Eye and Ear Infirmary, Boston, Massachusetts, and ${ }^{2}$ Yale University School of Medicine, New Haven, Connecticut, USA

SUMMARY A 52-year-old man with mild diabetes and acute stem cell leukaemia developed an orbitofacial mucormycosis. Cultures showed the fungus to be Rhizopus oryzae. Vigorous treatment with amphotericin B and with other bactericidal and bacteriostatic antibiotics for a concurrent sepsis failed to suppress the infections, and the patient died. On post-mortem examination characteristic haematoxylin-staining, broad, aseptate fungal hyphae were found in the right eye, orbit, and lung. A striking and unusual feature of this case is the presence of brightly biiefringent crystals within the severely degenerated eye. These were found by histochemical staining and $x$-ray diffraction studies to be calcium salts of fatty acids, apparently liberated from necrotic adipose tissue of the orbit.

Mucormycosis, or phycomycosis, is an infection caused by one of a variety of fungi belonging to the class Phycomycetes. Although these fungi are usually saprophytic and ubiquitous in nature, they can cause serious and rapidly fatal infections in man. Usually the patients who manifest this infection have a predisposing debilitating condition, among the most common of which are diabetes with acidosis, diarrhoea and dehydration, renal failure, cirrhosis, leukaemia or other lymphoproliferative disorders, and severe burns. In addition steroids, antibiotics, and cytotoxic agents have been strongly implicated both clinically and experimentally as predisposing agents for this infection. Excellent reviews of this subject are available (Hutter, 1959; McBride et al., 1960; Ferry, 1960; Gass, 1961a; Gass, 1961b; Straatsma et al., 1962; François and Rysselaere, 1972; Schwartz, 1977).

\section{Case report}

A 52-year-old white male with acute stem cell leukaemia developed a small, dark, gangrenous-

\footnotetext{
* Read before the Eastern Ophthalmic Pathology Society Meeting, McGill University, Montreal, Quebec, September 1976 (Dr Albert)
}

Correspondence to Dr Daniel M. Albert, Howe Laboratory, Massachusetts Eye and Ear Infirmary, 243 Charles Street, Boston, MA 02114, USA looking lesion in his right superior gingiva. One month prior to this admission he had been admitted to another hospital for evaluation of severe low back pain, the onset of which followed lifting a heavy load. Medical and neurological examinations at that time were within normal limits. Laboratory studies including complete and differential blood count, serum electrolytes, liver function tests, and acid phosphatase were within normal limits. A diagnosis of diabetes mellitus was made on the basis of raised fasting serum glucose and abnormal glucose tolerance test. Radiological examinations at the time of the first admission were within normal limits, with the exception of a possible ruptured lumbar disc. The diabetes was controlled by diet alone, and the patient was discharged on analgesics 1 week after admission.

At the time of the second admission the patient complained of persistent low back pain, loss of appetite, weight loss, and general malaise. Positive findings on physical examination included a palpable spleen, mild abdominal distension, and highly tympanic bowel sounds. A complete blood count revealed haemoglobin of $11 \cdot 2 \mathrm{~g} / \mathrm{dl}$, a white blood count of $22 \times 10^{9} / 1$ composed almost entirely of blast cells of stem cell or myeloblastic origin, and a platelet count of $98 \times 10^{9} / 1$. A diagnosis of acute stem cell leukaemia was made. Other laboratory studies and radiological examinations were within normal limits. 


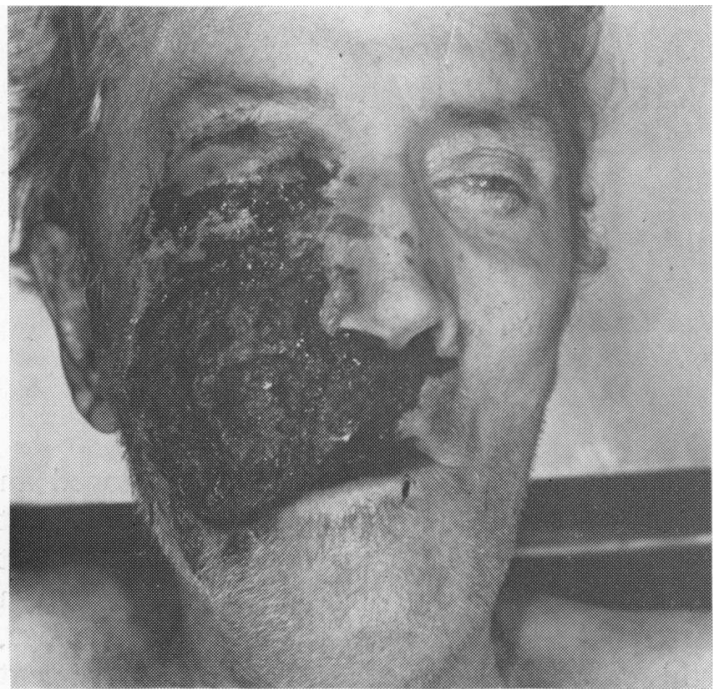

Fig. 1 Appearance of the patient with right orbitofacial mucormycosis

The patient was kept in isolation and was followed up with frequent peripheral and bone marrow smears. Treatment with a combination of thioguanine and cytosine arabinoside eventually led to anaplastic marrow and necessitated platelet and white blood cell transfusions.

Three weeks after the second admission the gingival lesion developed; within days it had spread to the cheek and soon involved the entire right side of the face (Fig. 1). Numerous attempts at bacterial culture from this widespread lesion were negative. Biopsy of the lesion showed numerous fungi with broad septate hyphae embedded in a matrix of chronic inflammatory cells and necrotic tissue. A culture of the fungus from the facial lesion was identified as Rhizopus oryzae. Treatment with intravenous amphotericin B was begun.

An ophthalmological examination was done about 2 weeks after the development of facial mucormycosis. It showed that vision in the right eye was of no light perception and in the left eye was $6 / 12(20 / 40)$ with best correction. The right periorbital area was necrotic and indurated. The right eye was proptosed $6 \mathrm{~mm}$, and no extraocular movements could be elicited. Manipulation of the right lids was done with difficulty because of pain and caused some bleeding. The cornea was ulcerated; the conjunctiva of the right eye showed severe injection. The right eye was softer to palpation than the left. On slit-lamp biomicroscopy of the right eye corneal ulceration was evident; the anterior chamber was deep, and no hypopyon was seen. Findings on slit-lamp biomicroscopy of the left eye were within normal limits. The iris, lens, and anterior vitreous body appeared normal on the right. The view of the right fundus was hazy, but no discrete vitreous or retinal lesions were seen. The overall impression was that of a right eye with no light perception owing to a phycomycosis of the right face and orbit. A right cavernous sinus thrombosis was highly suspected. Results of examination of the left eye were within normal limits.

Although treatment with amphotericin B seemed to prevent further extension of the facial lesion, the patient soon developed a partial atelectasis of the right lung, intestinal obstruction, and became septic, with Escherichia coli and a Bacteroides species being cultured from the blood. Treatment with gentamicin and cephalothin in addition to the amphotericin B did not lead to improvement of the patient's condition. The patient died in septic shock 6 weeks after admission to the hospital and approximately 3 weeks after developing the orbitofacial phycomycosis.

\section{PATHOLOGY}

Necropsy revealed a septicaemia, stem cell leukaemia, small bowel perforation with peritonitis and abscess formation, gastric mucosal petechiae, haemorrhagic pyelitis, splenic abscesses, and widespread mucormycosis, with fungi present in the entire right face, orbit, and eye as well as the lung.

Eye pathology (AFIP Accession No. 1546176). The right eye was found to be a necrotic grey-black mass measuring $21 \times 27 \mathrm{~mm}$. It had no identifiable external landmarks and did not transilluminate light. The cornea and pupil could not be identified. The optic nerve was $14 \mathrm{~mm}$ long and appeared normal. The globe was opened anteroposteriorly. The ciliary body and lens were not distinguishable. The vitreous was replaced by viscid, mottled material. The retina, choroid, and optic disc could not be identified on gross examination. The sclera was largely absent, but where present, was thickened.

Microscopically the right eye was found to be extremely disorganised, with marked degeneration of all layers (Fig. 2). Only small sections of sclera and optic nerve were intact. The remainder of the globe resembled fibrous and fatty tissues with a diffuse infiltration of strongly hematoxylin-staining long, broad, non-septate hyphae, consistent with a fungus belonging to the class Phycomycetes (Fig. 3). Within the globe were many crystals which stained intensely with alizarin red (Fig. 4), and were brightly birefringent when observed under polarised light. These crystals did not stain with haematoxylin and eosin, periodic acid-Schiff (PAS), Gromori methenamine silver (GMS), or von Kossa stain. Johnson's 'bubble test' for calcium oxalate was negative 
Fig. 2 Low-power view of right eye, showing extreme destruction $(H$ and $E \times 3 \cdot 7)$

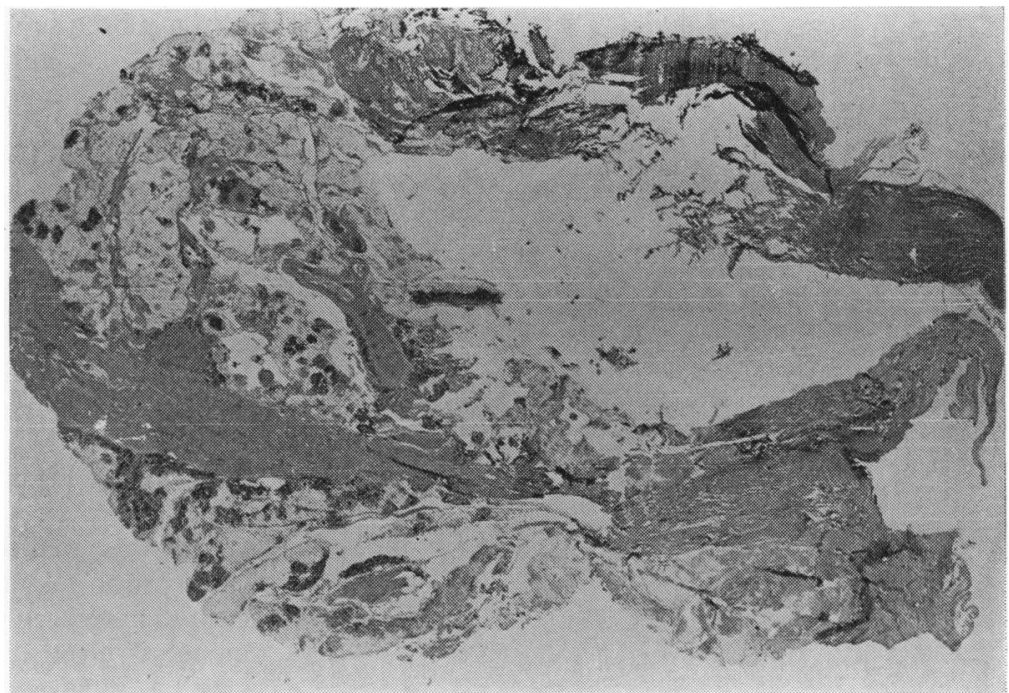

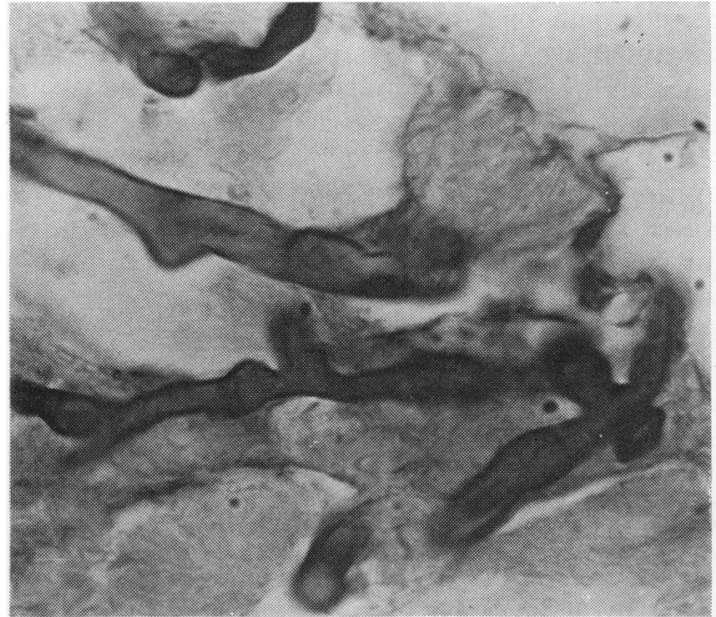

Fig. 3 Appearance of aseptate fungi typical of Phycomycetes ( $H$ and $E \times 410$ )

(Johnson, 1956). There were a number of foci of chronic inflammation composed of lymphocytes, plasma cells, macrophages, and scarce eosinophils, interspersed with hyphae. Occasional arterioles could be identified which were completely thrombosed by fungi and debris (Fig. 5). The optic nerve was atrophic and free of fungi. A diagnosis of Rhizopus oryzae panophthalmitis with degeneration of the globe and deposition of calcium salts of fatty acids was made.

The patient's left eye was grossly normal but microscopically showed early cataractous changes, peripheral retinal cystoid degeneration with schisis, and questionable early optic atrophy.

\section{Discussion}

This patient, like almost all patients who develop mucormycosis, was debilitated before infection. He had diabetes and leukaemia, and was being treated with cytotoxic agents for the latter. Thus there were 3 factors strongly predisposing to subsequent mucormycosis infection. His course was unusual in the fact that, although in most cases an orbitofacial mucormycosis originates in the nasal mucosa or paranasal sinuses, our patient had his infection originate in the gingival mucosa. Further, while

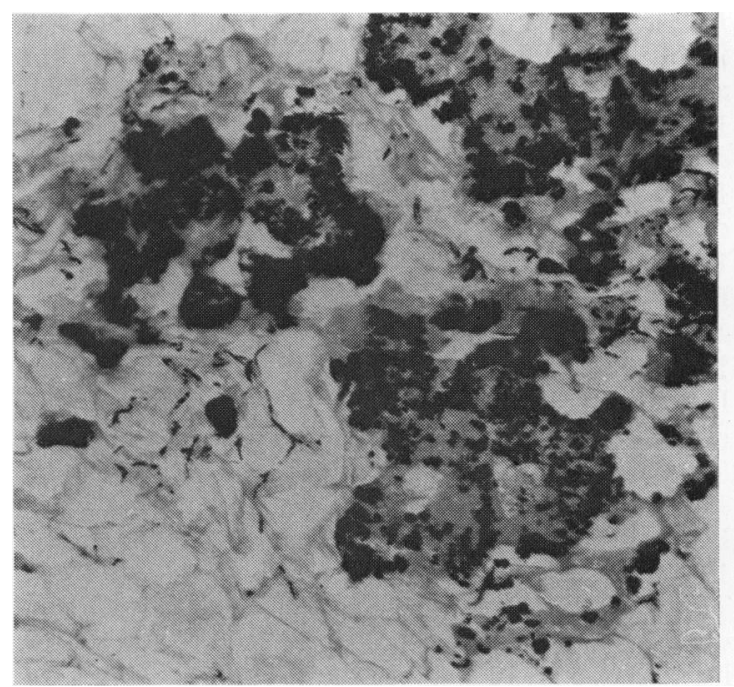

Fig. 4 Calcium crystal found within right eye (Alizarin red $\times 400$ ) 


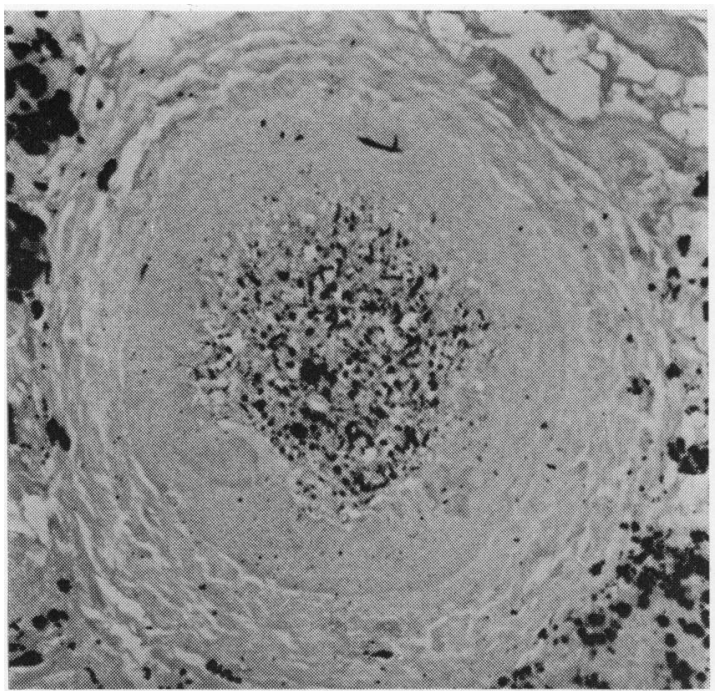

Fig. 5 Blood vessel thrombosed by fungi and debris, right eye ( $H$ and $E \times 365$ )

most cases of orbital mucormycosis go on to involve the meninges and brain, our patient had no clinical or histological evidence of intracranial involvement.

From an ophthalmological viewpoint the most common feature in mucormycosis is an orbital cellulitis. Many cases of this have been reported (Gregory et al., 1943; LeCompte and Meissmer, 1947; Stone, 1950; Martin et al., 1954; Bauer et al., 1955; Harris, 1955; Foushee and Beck, 1956; Johnson, 1956; Baker, 1957; McCall and Strobos, 1957; Bryan et al., 1958; Dwyer and Changus, 1958; Borland, 1959; Burns, 1959; Dolman and Herd, 1959; Faillo et al., 1959; Hutter, 1959; Long and Weiss, 1959; Berk, 1961; Ferry, 1961; Gass, 1961a; Gass, 1961b; Hoagland et al., 1961; Rabin et al., 1961; Wasserman et al., 1961; Bank et al., 1962; Straatsma et al., 1962; Lubbe, 1964; Lincoff et al., 1965; Parmentier et al., 1965; Ginsberg et al., 1966; Tomiyashu and Baker, 1966; Baum, 1967; Blodi et al., 1969; Fleckner and Ginsberg, 1969; Anco and Iriya, 1970; Best et al., 1971; Vergez et al., 1971; Georgiades et al., 1972; Bullock et al., 1974). Intraocular involvement in mucormycosis, diagnosed by the presence of fungi within the globe, is less common but has been reported (Gregory et al., 1943; Martin et al., 1954; Viers and Davis, 1958; Borland, 1959; Smith and Kirchner, 1958; Ferry, 1961; Wasserman et al., 1961; Ginsberg et al., 1966; Tomiyasu and Baker, 1966; Best et al., 1971). From our own experience as well as from a review of the literature this appears to be an extreme case of destruction of the eye by mucormycosis. One possible sequence of events in this diabetic patient may have been severe ketosis on terminal illness with deviation of metabolism to deposit fatty acids with subsequent calcification in this deposit. However, the rapid course which our patient had makes this an unlikely possibility.

It should be noted that 1 week before the patient's death an ophthalmological examination of the affected eye revealed corneal ulceration but an essentially normal anterior chamber, iris, and lens. No lesions of the vitreous and retina were noted. One week later pathological examination of the same eye after the patient's death showed these structures to be completely destroyed and unrecognisable. This demonstrates the rapidity of ocular destruction by this fungus even while the patient was treated by systemic amphotericin B. The question might be raised whether amphotericin $B$ would have been of value in preventing intraocular damage if given intracamerally and intravitreously as well as intravenously.

Of note in the histological findings was the presence of birefringent crystals within the degenerated eye. These crystals were not found elsewhere at necropsy. No similar report of such crystals occurring in a similar case could be found in our review of the literature. Possibly this finding was overlooked in previously reported cases, and we would recommend examining any tissue infected by this fungus with polarised light. Although Wadsworth (1951) mentioned that 'numerous cholesterin crystals' were embedded in a fibrous tissue scar behind the macula in an eye destroyed by mucormycosis, a careful review of his tissue sections by Straatsma et al. (1962) revealed that what were initially thought to be fungi within the eye were probably mineralised retinal capillaries.

Finally, it should be noted that the fungi in our patient are seen more easily with haematoxylin than with GMS, the stain usually used to demonstrate fungus. This confirms the previous finding of Straatsma et al. (1962) that these fungi had a greater affinity for haematoxylin than for PAS, GMS, or Grindley's stain.

We thank Dr L. E. Zimmerman for reviewing this article and $\operatorname{Dr} \mathrm{F}$. B. Johnson for performing the $x$-ray diffraction studies.

\section{References}

Anco, M. F., and Iriya, K. (1970). Ficomicose orbito-rinocerebral associada a cetacidose diabetica. Revista do Instituto de Medicina Tropical de Sao Paulo, 12, 354-363.

Baker, R. D. (1957). Mucormycosis-a new disease? Journal of the American Medical Association, 163, 805-808.

Bank, H., Shibolet, S., Gilat, T., Allman, G., and Heller, H. (1962). Mucormycosis of head and neck structures. British Medical Journal, 1, 766-768.

Bauer, H., Ajello, L., Adams, E., and Hernandez, D. V. 
(1955). Cerebral mucormycosis: Pathogenesis of the disease. American Journal of Medicine, 18, 822-831.

Baum, J. L. (1967). Rhinoorbital mucormycosis in an otherwise apparently healthy individual. American Journal of Ophthalmology, 63, 335-339.

Berk, M., Fink, G. I., and Uyeda, C. T. (1961). Rhinomucormycosis. Journal of the American Medical Association, 177, 511-513.

Best, M., Obstbaum, S. A., Friedman, B., and Strobos, R. J. (1971). Survival in orbital phycomycosis. American Journal of Ophthalmology, 71, 1078-1080.

Blodi, F. C., Hannah, F. T., and Wadsworth, J. A. C. (1969). Lethal orbito-cerebral phycomycosis in otherwise healthy children. American Journal of Ophthalmology, 67, 698-705.

Bryan, G. T., Read, C. R., and Zimmerman, G. R. (1958). Disseminated mucormycosis in a child with diabetes mellitus. Journal of the Iowa Medical Society, 48, 193-196.

Borland, D. S. (1959). Mucormycosis of the central nervous system. American Journal of Diseases of Children, 97, 852-856.

Bullock, J. D., Jampol, L. M., and Fezza, A. J. (1974). Two cases of orbital phycomycosis with recovery. American Journal of Ophthalmology, 78, 811-815.

Burns, R. P. L. (1959). Mucormycosis of the sinuses, orbit, and central nervous system. Pacific Coast Otolaryngological-Ophthalmological Society, 40, 83-101.

Dolman, C. L. A., and Herd, A. J. (1959). Acute pancreatitis in pregnancy complicated by renal cortical necrosis and cerebral mucormycosis. Canadian Medical Association Journal, 81, 562-564.

Dwyer, G. K., and Changus, G. W. (1958). Rhinomucormycosis resulting in fatal cerebral mucromycosis. Archives of Otolaryngology, 67, 619-623.

Faillo, P. S., Sube, H. S., and Anderson, N. H. (1959). Mucormycosis of the paranasal sinuses and maxilla. Oral Surgery, Oral Medicine, and Oral Pathology, 12, 304-309.

Ferry, A. P. (1961). Cerebral mucormycosis (phycomycosis). Survey of Ophthalmology, 6, 1-24.

Fleckner, R. A., and Goldstein, J. H. (1969). Mucormycosis. British Journal of Ophthalmology, 53, 542-548.

Francois, J., and Rysselaere, M. (1972). Oculomycosis. Charles C Thomas: Springfield, Illinois.

Foushee, S., and Beck, W. C. (1956). Mucormycosis of the central nervous system. North Carolina Medical Journal, $17,26-31$.

Gass, J. D. M. (1961a). Acute orbital mucormycosis. Archives of Ophthalmology, 65, 214-220.

Gass, J. D. M. (1961b). Ocular manifestations of acute mucormycosis. Archives of Ophthalmology, 65, 226-237.

Georgiades, G., Argalias, A., Dracoulis, P., and Stamoulis, V. (1972). Mucormycose naso-orbito-oculaire. Annales d'Oculistique, 205, 721-734.

Ginsberg, J., Spaulding, A. G., and Liang, V. O. (1966). Cerebral phycomycosis (mucormycosis) with ocular involvement. American Journal of Ophthalmology, 62 , 900-906.

Gregory, J. E., Golden, A., and Haymaker, W. (1943). Mucormycosis of the central nervous system. Bulletin of the Johns Hopkins Hospital, 73, 405-419.

Harris, J. S. (1955). Mucormycosis. Pediatrics, 16, 857-867.
Hoagland, R. J., Sube, J., Bishop, R. H., and Holding, B. F. (1961). Mucormycosis. American Journal of the Medical Sciences, 242, 415-422.

Hutter, R. V. P. (1959). Phycomycosis infection (mucormycosis) in cancer patients-a complication of therapy. Cancer, 12, 330-350.

Johnson, F. B. (1956). A method for demonstrating calcium oxalate in tissue sections. Journal of Histochemistry, 4, 404-405.

LeCompte, P. M., and Meissner, W. A. (1947). Mucormycosis of the central nervous system associated with hemochromatosis. American Journal of Pathology, 23, 673-677.

Lincoff, H. A., McLean, J. M., and Nano, H. (1965). Scleral abcess. Archives of Ophthalmology, 74, 641-648.

Long, E. L., and Weiss, D. J. (1959). Cerebral mucormycosis. American Journal of Medicine, 26, 625-635.

Lubbe, T. R., and Pennington, J. S. (1964). Orbital mucormycosis. Medical Journal of Australia, 1, 681-683.

McBride, R. A., Corson, J. A., and Dammin, G. J. (1960) Mucormycosis. American Journal of Medicine, 28, 832-846.

McCall, W., and Strobos, R. R. J. (1957). Survival of a patient with central nervous system mucormycosis. Neurology, 7, 290-292.

Martin, F. P., Lukeman, J. M., Ranson, R. F., and Geppert, L. J. (1954). Mucormycosis of the central nervous system associated with thrombosis of the internal carotid artery. Journal of Pediatrics, 44, 437-442.

Parmentier, N., Balasse, J., and Vanderhaegen, J. J. (1965). Orbital mucormycosis. Clinical and anatomic survey and review of the literature. Archives d'Ophtalmologie, 25, 689-704.

Rabin, E. R., Lundberg, G. D., and Mitchell, E. T. (1961). Mucormycosis in severely burned patients. New England Journal of Medicine, 264, 1286-1289.

Schwartz, J. A., Donnelly, E. H., and Klintworth, G. K, (1977). Review: ocular and orbital phycomycosis. Survey of Ophthalmology, 22, 2-28.

Smith, H. W., and Kirchner, J. A. (1959). Cerebral mucormycosis. Archives of Otolaryngology, 68, 715-726.

Smith, H. W., and Yanagisawa, E. (1959). Rhinomycormycosis. New England Journal of Medicine, 260, 1007-1012.

Stone, W. C. (1950). Mucormycosis of the eye: report of a case. Archives of Ophthalmology, 44, 746-747.

Straatsma, B. R., Zimmerman, L. E., and Gass, J. D. M. (1962). Phycomycosis: a clinicopathologic study of fiftyone cases. Laboratory Investigation, 11, 963-985.

Tomiyasu, U., and Baker, R. M. (1966). Phycomycosis (mucormycosis) of the orbital apex and cavernous sinus. Bulletin of the Los Angeles Neurological Society, 31, 177-195.

Vergez, A., Baltriz, C., Pointud, P., and Salvanet, A. (1971). Mycose orbitocerebrale. Annales d'Oculistique, 204, 285296.

Viers, E. R., and Davis, T. (1958). Fungus infections of the eye and orbit. Archives of Ophthalmology, 59, 172-176.

Wadsworth, J. A. (1951). Ocular mycormycosis. American Journal of Ophthalmology, 34, 405-409.

Wasserman, A. J., Shiels, W. D., and Sporn, I. N. (1961) Cerebral mucormycosis. Southern Medical Journal, 54, 403-410. 